\title{
Panels Track Chairs' Welcome
}

It is our great pleasure to welcome you to the WWW 2018 Panels Track. We have selected three panel proposals among the ones received. We also took in account the coverage of the different areas related to WWW, inputs from the community with a shared document, as well as the suggestions of the authors of the research tracks in deciding the subjects of the three panels.

The first day includes the following two panels:

- "The shifting landscape of Web search and mining: past, present, and future" moderated by Davood Rafiei (University of Alberta)

- "Panel on Cognitive Service Engineering" moderated by Boualem Benatallah (University of New South Wales) and Fabio Casati (University of Trento and Tomsk Polytechnic University)

The final day includes the following panel:

- "Structured Knowledge on the Web 7.0" moderated by Steffen Staab (Institute WeST, Universität Koblenz-Landau and Web and Internet Science Research Group, University of Southampton)

We believe that the program provides a good balance among several trending topics such as the evolution of the web (D. Rafiei), crowdsourcing, web services and novel web usages (B. Benatallah and F. Casati), and the future of knowledge bases (S. Staab). Hence we hope that you will find the panel program interesting, providing you with a valuable opportunity to learn and share ideas with other researchers and practitioners from institutions around the world.

Angela Bonifati

Panels Track Chair

Lyon 1 University
Romain Vuillemot

Panels Track Chair

École Centrale de Lyon

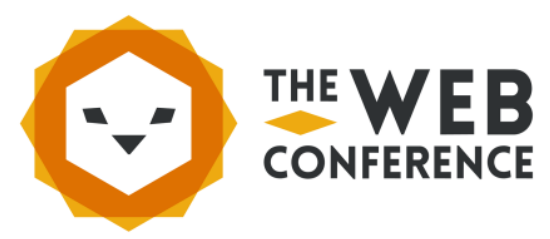

